\title{
Identification of factors related to food insecurity and the implications for social determinants of health screenings
}

\author{
Ashley R. Banks ${ }^{1 *} \mathbb{D}$, Bethany A. Bell ${ }^{2}$, David Ngendahimana ${ }^{3}$, Milen Embaye ${ }^{3}$, Darcy A. Freedman ${ }^{3}$ and \\ Deena J. Chisolm ${ }^{1,4}$
}

\begin{abstract}
Background: Food insecurity and other social determinants of health are increasingly being measured at routine health care visits. Understanding the needs and behaviors of individuals or families who screen positive for food insecurity may inform the types of resources they need. The goal of this research was to identify modifiable characteristics related to endorsement of two food insecurity screener questions to better understand the resources necessary to improve outcomes.

Methods: Analysis was conducted focusing on cross-sectional survey data collected in 2015-2016 from participants $(N=442)$ living in urban neighborhoods in Ohio with limited access to grocery stores. Food insecurity was assessed by the endorsement of at least one of two items. These were used to categorize participants into two groups: food insecure $(N=252)$ or food secure $(N=190)$. Using logistic regression, we estimated the association between several variables and the food insecure classification.

Results: Those that used their own car when shopping for food had lower odds of reporting food insecurity, as did those with affirmative attitudes related to the convenience of shopping for and ease of eating healthy foods. As shopping frequency increased, the odds of food insecurity increased. Food insecurity also increased with experience of a significant life event within the past 12 months. There was an $81 \%$ increase in the odds of reporting food insecurity among participants who received Supplemental Nutrition Assistance Program benefits compared to those not receiving Supplemental Nutrition Assistance Program benefits.

Conclusions: Along with referrals to SNAP, clinicians can further address screening-identified food insecurity through provision of transportation supports and linkages to other social services while collaborating on community initiatives to promote convenient and easy access to healthy foods. The needs and behaviors associated with screens indicating food insecurity also have implications for impacting other SDH, and thus, health outcomes.
\end{abstract}

Keywords: Social determinants of health screening, Food insecurity, Health disparities

\footnotetext{
* Correspondence: Ashley.Banks@nationwidechildrens.org

${ }^{1}$ Center for Child Health Equity and Outcomes Research, The Abigail Wexner

Research Institute at Nationwide Children's Hospital, 700 Children's Drive,

Columbus, OH 43205, USA

Full list of author information is available at the end of the article
}

C C The Author(s). 2021 Open Access This article is licensed under a Creative Commons Attribution 4.0 International License, which permits use, sharing, adaptation, distribution and reproduction in any medium or format, as long as you give appropriate credit to the original author(s) and the source, provide a link to the Creative Commons licence, and indicate if changes were made. The images or other third party material in this article are included in the article's Creative Commons licence, unless indicated otherwise in a credit line to the material. If material is not included in the article's Creative Commons licence and your intended use is not permitted by statutory regulation or exceeds the permitted use, you will need to obtain permission directly from the copyright holder. To view a copy of this licence, visit http://creativecommons.org/licenses/by/4.0/. The Creative Commons Public Domain Dedication waiver (http://creativecommons.org/publicdomain/zero/1.0/) applies to the data made available in this article, unless otherwise stated in a credit line to the data. 


\section{Background}

In 2018 , approximately $11.1 \%$ of all US households and $13.9 \%$ of households with children experienced one of the most common social determinants of health (SDH), food insecurity [1]. The US Department of Agriculture (USDA) defines food insecurity in two levels. The first, low food security, represents reduced quality, variety, or desirability of diet yet little or no indication of reduced food intake. The second is very low food security, which includes reports of multiple indications of disrupted eating patterns and reduced food intake [2]. Food insecurity is most often the result of a combination of financial and structural barriers and research demonstrates that it affects the health and well-being of individuals by contributing to higher rates of obesity, fewer heathy foods served at meals, lower quality diets, mental distress, and functional limitations [3-6]. These consequences differ based on demographic characteristics (i.e., race, ethnicity, and age) contributing to health inequities across populations $[7,8]$. In addition to these consequences, food insecurity is directly associated with dietary behaviors and perceptions $[9,10]$. Despite some food insecure individuals perceiving healthy eating as beneficial to health, many also view it as inconvenient [9]. Balancing a value for healthy eating with the need to stretch food budgets sometimes results in dietary behaviors (i.e., reducing fruit and vegetable purchases) that have negative implications for health $[11,12]$.

Based on the potential for food insecurity and other $\mathrm{SDH}$ to impact health outcomes, screening in primary care settings has been discussed as a means to help providers identify needs and address issues through referrals to additional resources [13]. In 2015, the American Academy of Pediatrics (AAP) recommended screening for food insecurity in children through the use of a twoitem screener called the Hunger Vital Sign ${ }^{\text {TM }}$ screening tool, which addresses worry about food insecurity and experiencing food insecurity [14]. The Hunger Vital $\operatorname{Sign}^{\mathrm{TM}}$ has been used in a variety of clinical settings, with mixed results in acceptability by patients and providers and in effectiveness for identification of food insecurity and subsequent referral to resources. Barriers related to using this tool include patient refusals, patient discomfort in talking about food needs with providers, perceptions of ineligibility for supportive services, and challenges in implementation of referral processes for families who indicate a need for food resources [15-17].

Despite these barriers, screening for food insecurity and other SDH in primary care settings may result in more referrals and thus the potential for more individuals or families to access needed community resources [18]. In addition, screening may help providers better understand factors influencing their patients' health outcomes, and further, identify the need for resources that go beyond provision of food for a family. However, even with the potential value of screening for food insecurity, implementation can have substantial operational cost. The value of such screening is ultimately defined by the usefulness of the data collected. Brief SDH screening items, like those recommended by the AAP and other bodies, provide limited information about a person's actual needs and little is known about the demographic, attitudinal, or behavioral characteristics associated with a positive screen for food insecurity. The present analysis aimed to identify needs and behaviors related to the endorsement of two food insecurity screener questions like those included in the Hunger Vital Sign ${ }^{\mathrm{Ts}}$. The goal of this work is not to validate a new screening tool, but instead to identify potential intervention targets in those individuals endorsing screening items.

\section{Methods}

\section{Study population}

This analysis uses baseline data from a longitudinal natural experiment investigating the impact of the food retail environment on dietary behaviors [19]. Participants were recruited from two urban neighborhoods in Cleveland and Columbus, Ohio, each identified as low-income and having low access to healthy food. The two neighborhoods have similar racial and economic composition (i.e., majority African American, approximately 40\% received Supplemental Nutrition Assistance Program [SNAP] benefits) and access to healthy food retailers.

Participants were recruited from August 2015 to July 2016 using mailings, flyers, public presentations, and word-of-mouth. Interested individuals were invited to complete the baseline surveys if they were 1) at least 18 years old, 2) living in a targeted census tract, 3) intending to remain in their current neighborhood for at least 12 months, 4) the primary food shopper of the household, and 5) English speaking. A total of 1395 individuals were screened for eligibility, of which 655 were eligible. Ineligibility was mainly due to living outside of the targeted geographic area. Of the eligible participants, 516 completed the three surveys. From the 516, we limited the sample to those who had complete data on the variables to be included in the logistic regression, which are found in Table 2 below, bringing the final sample to 442 participants. Name Redacted Institutional Review Board issued approval for study activities, and participants completed the informed consent process prior to participation.

\section{Data collection}

Data collection occurred from August 2015 to September 2016. Survey data included three 24-h dietary recalls and a psychosocial survey. Surveys and recalls were conducted by trained research staff over the phone within a 
37-day timeframe to reduce seasonal variability in diet. The 24-h dietary recalls used a standardized multi-pass approach. Materials needed to support data collection were mailed to participants prior to administration of the surveys. Participants were compensated $\$ 110$ for completing the three surveys. A more detailed description of the study protocol is provided elsewhere [19].

\section{Measures \\ Shopping behaviors, demographics, attitudes}

Characteristics related to shopping were measured by asking participants to name the two food retailers where most of their food was purchased, the types of retailers used, frequency of food shopping, and method of transportation. Frequency of food shopping was operationalized as monthly shopping, and it was windsorized at the 95th percentile. Participants were given multiple options for method of transportation, and the variable was operationalized as shopping with their own car or not. Demographic information including sex, education level, employment status, annual household income, and race were self-reported by participants using categorical response options. Experiencing a significant life change was defined as self-report of any of the following within the past 12 months: death of a loved one, major illness, job loss, or birth of a child. Chronic disease was defined as endorsing at least one of 11 chronic diseases included on a list (i.e. heart disease, diabetes, asthma). Participants were also asked questions related to the ease, affordability, and convenience of purchasing and eating healthy foods, using a 4-point Likert scale.

\section{Food security screening}

The measure of food insecurity for this analysis included endorsing at least one of two items. The first, from the Behavioral Risk Factor Surveillance System(BFRSS), was "How often in the past 12 months would you say you were worried or stressed about having enough money to buy nutritious meals?" and included a 5-point Likert scale for response with answers ranging from "always" to "never" [20]. Participants were coded as endorsing this statement if they had a response of always, usually, or sometimes. The second item, which was drawn from the USDA food security screening tool and the AAP Hunger Vital Sign ${ }^{\text {Tu }}$ tool, asked participants to choose from 3 responses ("often true", "sometimes true", and "never true") to indicate how often they felt the following statement to be true for themselves or their household over the past 12 months: "The food that (I/we) bought just didn't last, and (I/we) didn't have money to get more." Participants were coded as endorsing this item if they responded often true or sometimes true. This combination of items was selected to meet the needs of the underlying community food insecurity intervention study.

\section{Healthy eating index}

Healthy Eating Index-2010 (HEI-2010) scores were calculated based on self-reported 24-h dietary recall data collected via the Nutrition Data System for Research. HEI-2010 scores are a measure of diet quality based on conformity to the 2010 Dietary Guidelines for Americans [21]. Based on the three 24-h dietary recalls, an average HEI-2010 score was calculated, with higher average scores $($ maximum $=100)$ indicating increased alignment with dietary guidelines and better diet quality.

\section{Statistical analysis}

Descriptive statistics (means and standard deviations for continuous variables and frequency tables for categorical variables) were computed, and t-tests and chi-squared tests were used to test for differences between participants reporting food insecurity and those in the food secure group. The results of these comparisons can be found in Table 1. Binary logistic regression was used to estimate the odds of being food insecure adjusting for the predictors listed in Table 2. The use of SNAP, rather than income, was chosen because the two are related, however, SNAP has greater practice implications given that providers can refer for SNAP, but not for an increased income. This approach concurrently estimates the effects of any listed variable on food security status while controlling for potential confounders. The food secure group was the reference group for the outcome. There was no evidence of multicollinearity in the fully adjusted models (tolerance values ranged from .74 to .98). Given the relatively small amount of missing data (6\% of items across all participants were missing) and determining that data were missing at random, listwise deletion was used to limit the analytic sample to those with complete data on all variables included in the logistic regression models [22]. Analyses were conducted in 2019 using SAS, version 9.4.

\section{Results \\ Sample characteristics}

The study population included 442 people. Most participants were female $(75.9 \%)$ and unmarried $(84.4 \%)$. The average age of respondents was 51 years old $(\mathrm{SD}=13.2$ years), and $67.5 \%$ of the total respondents were Black. The average household size was slightly less than the national average in 2015(2.5 people per household), at 2.46 people in the food insecure group, and 2.19 people in the food secure group. Nearly two-thirds of the respondents (62.2\%) reported having a high school education or less, and less than $39 \%$ of respondents were employed 
Table 1 Sample Characteristics of Respondents by Food Security Status

\begin{tabular}{|c|c|c|c|}
\hline Variable & Food Insecure & Food Secure & $p$-value \\
\hline \multicolumn{4}{|l|}{ Sociodemographic Characteristics } \\
\hline Married (\%) & $34(13.5)$ & $35(18.4)$ & 0.2 \\
\hline Black (\%) & $178(70.6)$ & $115(60.5)$ & 0.084 \\
\hline Female (\%) & $194(77.0)$ & $139(73.2)$ & 0.11 \\
\hline Education level of high school or less (\%) & $165(65.5)$ & $110(57.9)$ & 0.126 \\
\hline Employment (\%) & & & $<0.001$ \\
\hline A homemaker & $8(3.2)$ & $1(0.5)$ & \\
\hline A student & $2(0.8)$ & $2(1.1)$ & \\
\hline Employed for Wages & $88(34.9)$ & $83(43.7)$ & \\
\hline Out of work for $<1$ year & $28(11.1)$ & $8(4.2)$ & \\
\hline Out of work for $>1$ year & $15(6.0)$ & $12(6.3)$ & \\
\hline Refused to work & $0(0.0)$ & $3(1.6)$ & \\
\hline Retired & $20(7.9)$ & $33(17.4)$ & \\
\hline Self-employed & $10(4.0)$ & $8(4.2)$ & \\
\hline Unable to work & $81(32.1)$ & $40(21.1)$ & \\
\hline Number of people living in household (mean (SD)) & $2.46(1.51)$ & $2.19(1.30)$ & 0.049 \\
\hline Experienced significant changes in life in past year (\%) & $113(44.8)$ & $56(29.5)$ & $<0.001$ \\
\hline Receives SNAP benefits (\%) & $184(73.0)$ & $104(54.7)$ & $<0.001$ \\
\hline Income & & & $<0.001$ \\
\hline Less than $\$ 10,000$ & $116(46.0)$ & $51(26.8)$ & \\
\hline$\$ 10,000-\$ 20,000$ & $82(32.5)$ & $54(28.4)$ & \\
\hline$\$ 20,001-\$ 30,000$ & $32(12.7)$ & $35(18.4)$ & \\
\hline Over $\$ 30,000$ & $21(8.3)$ & $50(26.3)$ & \\
\hline \multicolumn{4}{|l|}{ Health Information } \\
\hline Have health insurance (\%) & $234(92.9)$ & $178(93.7)$ & 0.839 \\
\hline Chronic disease (\%) & $138(54.8)$ & $86(45.3)$ & 0.06 \\
\hline \multicolumn{4}{|l|}{ Food Shopping and Dietary Behaviors } \\
\hline Frequency of food shopping at primary store in days per month (mean (SD)) & $4.85(5.62)$ & $3.82(4.17)$ & 0.034 \\
\hline Shops with own car (\%) & $117(46.4)$ & $117(61.6)$ & 0.002 \\
\hline 2010 Healthy Eating Index score (mean (SD)) & $48.73(9.51)$ & $51.98(10.82)$ & $<0.001$ \\
\hline \multicolumn{4}{|l|}{ Beliefs about Food Shopping and Diet } \\
\hline I have enough time to shop for fresh and healthy foods. (\%) & & & 0.056 \\
\hline Strongly Agree & $143(56.7)$ & $127(66.8)$ & \\
\hline Tend to Agree & $81(32.1)$ & $54(28.4)$ & \\
\hline Tend to Disagree & $19(7.5)$ & $6(3.2)$ & \\
\hline Strongly Disagree & $9(3.6)$ & $3(1.6)$ & \\
\hline It is convenient for me to purchase fresh and healthy food. (\%) & & & $<0.001$ \\
\hline Strongly Agree & $124(49.2)$ & $111(58.4)$ & \\
\hline Tend to Agree & $76(30.2)$ & $65(34.2)$ & \\
\hline Tend to Disagree & $33(13.1)$ & $13(6.8)$ & \\
\hline Strongly Disagree & $19(7.5)$ & $1(0.5)$ & \\
\hline Eating a fresh and healthy diet is affordable (\%) & & & 0.001 \\
\hline Strongly Agree & $56(22.2)$ & $50(26.3)$ & \\
\hline Tend to Agree & $86(34.1)$ & $82(43.2)$ & \\
\hline
\end{tabular}


Table 1 Sample Characteristics of Respondents by Food Security Status (Continued)

\begin{tabular}{|c|c|c|c|}
\hline Variable & Food Insecure & Food Secure & $p$-value \\
\hline Tend to Disagree & $67(26.6)$ & $48(25.3)$ & \\
\hline Strongly Disagree & $110(43.7)$ & $58(30.5)$ & \\
\hline It is easy to eat a fresh and healthy diet (\%) & & & $<0.001$ \\
\hline Strongly Agree & $68(27.0)$ & $75(39.5)$ & \\
\hline Tend to Agree & 89 (35.3) & $76(40.0)$ & \\
\hline Tend to Disagree & $62(24.6)$ & $32(16.8)$ & \\
\hline Strongly Disagree & $33(13.1)$ & $7(3.7)$ & \\
\hline
\end{tabular}

Notes: 1. Boldface $p$-values indicate statistical significance $(p<0.05)$

2. Differences between continuous items were assessed using independent means t-tests and differences between categorical items were assessed using chi-square tests

3. Sample sizes for items differ due to missing data

for wages. Nearly all respondents $(95.2 \%)$ had health insurance at the time of survey data collection.

\section{Demographics and attitudes}

A summary of participant characteristics delineated by food insecurity status is included in Table 1. Participants were considered part of the food insecure group if they endorsed at least one of the two food insecurity questions, and in the food secure group if they did not endorse either item. Over half of the respondents (57\%) answered affirmatively to at least one of the two food insecurity screening items. These participants $(n=252)$ were considered food insecure for this analysis. Those in the food insecure group were more likely to report having a chronic illness, though only marginally significant $(p=0.06)$, and significantly less likely to describe a fresh healthy diet as "easy", "affordable," or "convenient" ( $p<$ $0.001)$.

\section{Diet and food behaviors}

Those in the food insecure group had significantly lower HEI-2010 scores $(p<0.001)$, indicating a lower overall diet quality. Most in the food insecure group (73\%) received SNAP benefits. Food insecure participants shopped with significantly more frequency (4.9 days per month) than their counterparts who were categorized as food secure (3.8 days per month) $(p<0.05)$. Despite shopping more frequently, fewer food insecure participants utilized their own car for food shopping than those who were food secure (46.4\% compared to $61.6 \%$, respectively) $(p=0.002)$.

\section{Multivariable analyses}

Using a logistic regression model, we estimated the association between several variables and the food insecure classification based on the two-item screener. Table 2 displays the odds ratios and associated $p$-values for 11

Table 2 Multivariable Association Between Select Characteristics and Food Security Status

\begin{tabular}{|c|c|c|}
\hline Variable & Estimate (SE) & OR $(95 \% \mathrm{Cl})$ \\
\hline \multicolumn{3}{|l|}{ Sociodemographic Characteristics } \\
\hline Education level of high school or less & $0.315(-0.137,0.766)$ & $1.37(0.872,2.151)$ \\
\hline Receives SNAP benefits & $0.591(0.129,1.052)$ & $1.805(1.138,2.864)$ \\
\hline Experienced significant changes in life in past year & $0.63(0.196,1.064)$ & $1.877(1.216,2.899)$ \\
\hline \multicolumn{3}{|l|}{ Health Information } \\
\hline Chronic disease & $0.462(0.041,0.883)$ & $1.587(1.042,2.417)$ \\
\hline \multicolumn{3}{|l|}{ Food Shopping and Dietary Behaviors } \\
\hline Store 1 shopping frequency in months & $0.099(0.032,0.166)$ & $1.104(1.033,1.18)$ \\
\hline Shops with own car & $-0.589(-1.038,-0.14)$ & $0.555(0.354,0.869)$ \\
\hline 2010 Healthy Eating Index score & $-0.02(-0.042,0.002)$ & $0.98(0.959,1.002)$ \\
\hline \multicolumn{3}{|l|}{ Beliefs about Food Shopping and Diet } \\
\hline I have enough time to shop for fresh and healthy foods & $-0.265(-0.6,0.07)$ & $0.767(0.549,1.072)$ \\
\hline It is convenient for me to purchase fresh and healthy food & $-0.304(-0.605,-0.003)$ & $0.738(0.546,0.997)$ \\
\hline Eating a fresh and healthy diet is affordable & $-0.17(-0.425,0.084)$ & $0.844(0.654,1.088)$ \\
\hline It is easy to eat a fresh and healthy diet & $-0.317(-0.58,-0.056)$ & $0.728(0.56,0.946)$ \\
\hline
\end{tabular}

Note: Boldface indicates statistical significance $(p<0.05)$ 
characteristics included in the model. Affirmative attitudes related to convenience of shopping for healthy foods $[\mathrm{OR}=0.74 ; 95 \% \mathrm{CI}=(0.55,1.00)]$ and ease of eating healthy foods $[\mathrm{OR}=0.73 ; 95 \% \mathrm{CI}=(0.56,0.95)]$ were associated with decreased odds of reporting food insecurity. Similarly, those that used their own car when shopping for food had lower odds of reporting food insecurity $[\mathrm{OR}=0.55 ; 95 \% \mathrm{CI}=(0.35,0.87)]$.

Compared to those who did not report having any chronic disease, among those with a with a chronic disease, we see a $59 \%$ increase in the odds of food insecurity $[\mathrm{OR}=1.59 ; 95 \% \mathrm{CI}=(1.04,2.42)]$. As shopping frequency increased, the odds of food insecurity also increased $[\mathrm{OR}=1.10 ; 95 \% \mathrm{CI}=(1.03,1.18)]$. The odds of reporting food insecurity also increased when participants experienced a significant life event within the past 12 months $[\mathrm{OR}=1.88 ; 95 \% \mathrm{CI}=(1.22,2.90)]$. Participants that received SNAP benefits are expected to have an $81 \%$ increase in the odds of reporting food insecurity, compared to those not receiving SNAP benefits [OR = $1.81 ; 95 \% \mathrm{CI}=1.14,2.86)]$. HEI-2010 scores, education, and perceptions of affordability and time associated with healthy foods did not produce statistically significant results.

\section{Discussion}

This cross-sectional survey found that over half of the participants experienced food insecurity. Study participants were from households located in two midwestern urban neighborhoods with low access to healthy food retailers. Our finding that those with chronic conditions have higher odds of food insecurity underscores the clinical relevance of brief screening. These results also highlight the fact that universal clinic-based screening by providers serving these communities may identify high levels of need beyond food resources, which may present new challenges and opportunities.

One of the most common actions taken in response to a positive screen for food insecurity in the clinical setting is referral to Supplemental Nutrition Assistance Program (SNAP) [17, 23]. The fact that nearly threequarters of the households experiencing food insecurity in our survey were already receiving SNAP suggests that this approach is necessary but not always sufficient for meeting food needs. Residual food insecurity in the SNAP population has been linked to factors including negative income shocks or changes in household composition [24]. It might also be driven by associations with other non-random correlates of SNAP participation [25]. Other supplemental low cost or no cost food sources, including community-based food pantries and nutrition incentive programs like Double Up Food Bucks $[26,27]$, should be included in the food insecurity referral model.
Another explanation for this finding is that SNAP benefits may not surmount food access barriers beyond costs. Those who described a fresh and healthy diet as affordable, easy, or convenient had lower odds of screening positive for food insecurity. These attitudes related to ease or convenience may align with food insecure respondents' greater number of shopping trips and the greater need to use transportation other than their own car. Other research on shopping patterns has shown that food insecure families travel shorter distances to complete their grocery shopping [28], which may indicate transportation barriers as limitations to shopping in stores beyond that of corner or convenience stores that tend to offer fewer healthy options. However, findings on the type of retailers that food insecure individuals frequent for food purchasing have been mixed [12, 13, 28]. As such, responses to food insecurity needs may be most successful when they include instrumental supports (e.g., bus passes, taxi vouchers, food delivery, ready-to-eat meal kits) that help people work around barriers, and motivational interviewing to support changes in attitudes toward and perceptions of healthy eating and food shopping behaviors. Supports to reduce the transportation barrier related to food access also has implications for access to health care and other services that may otherwise be limited by lack of transportation. Findings emphasize the value of clinical-community linkages that extend healthcare services to include strategic connections with community services. This may include connections to food-related services such as food pantries, nutrition education and navigation [29], nutrition incentive programs like Double Up Food Bucks, community gardens, and food stores that offer healthy foods at affordable prices as well as non-food related services such as transportation and financial supports [30]. The common approach of providing a list of resources related to social needs without facilitation of accessing these resources is likely not enough to generate lasting improvement [17].

It is important to recognize that food insecurity does not exist in a vacuum and may be a "symptom" of larger socioeconomic struggles. Consistent with previous research, our analysis found that significant life events, such as death of a loved one, legal troubles, change in finances, or job loss were nearly twice as common in those experiencing food insecurity [31]. The crosssectional nature of these data does not allow us to determine the direction of causation, but food insecurity is likely an indication of many needs, beyond just food [32]. Given the limited ability to control some of these life changes, resources related to coping or perhaps alleviating some of the burden that these events put on families may be feasible ways to prevent food insecurity among patients and their families. 
Based on the current analysis, we argue that the value of brief screening for food security in primary care starts with needs identification and referral yet expands to included considerations related to strategically connecting patient needs with both food and non-food related supports. These screenings reveal much more than worry about food. Accordingly, they provide a tool for tailoring health care delivery to effectively support patients or families in higher need of social, financial, and community resources.

\section{Limitations}

First, this study used two independent validated food insecurity items rather than a validated scale like the Hunger Vital Sign $^{\text {Tw }}$ tool. This measurement approach was selected to meet the needs of the primary study from which this data is drawn. As such, the results do not fully generalize to the food insecure populations generated from more standardized measurement approaches. Secondly, the cross-sectional nature of the study limits us to discussion of associations rather than causation. Next, given that food security can be transient, an individual could endorse at least one of the given questions at the time of interview, perhaps if they were feeling the effects more strongly at that point, and fluctuate throughout the year. However, the US Economic Research Service (ERS) reports that many households who experience food insecurity at some point in the year experienced this for 7 months during the year, suggesting that although perhaps transient, food insecurity can be persistent [1]. Thus, there may still be benefit in understanding that individuals have experienced food insecurity within the year, coupled with additional barriers or lack of resources.

The measure of food insecurity applied in this research included the use of two separately validated, nationally used items, rather than the use of one tool. Surveys utilized in this study were developed prior to the wide adoption and standardization of the two-item Hunger Vital Sign ${ }^{\text {tm. }}$. Finally, results provide insight into characteristics associated with food insecurity among a community sample rather than a clinical population. However, half of the study population reported a chronic illness and over $90 \%$ are insured.

\section{Conclusions}

Food insecurity is likely a common SDH among patients living in low-income urban neighborhoods with low access to grocery stores. In addition to screening for food insecurity within health care settings, findings offer suggestions for the types of community-clinical linkages that may need to be fostered to effectively treat patients experiencing food insecurity and potentially lacking other resources related to $\mathrm{SDH}$. Findings suggest effective referral mechanisms to both food and non-food related community services are warranted within health care systems to modulate SDH and the effect they have on health outcomes. The available research related to SDH screening points to the importance of understanding characteristics and needs of patients for them to achieve the best health outcomes. Seamless connections linking patients to community resources-allowing for feedback within the health care setting-will be needed to optimize public health impact.

\section{Abbreviations \\ SDH: Social determinants of health; USDA: US Department of Agriculture; AAP: American Academy of Pediatrics; SNAP: Supplemental Nutrition Assistance Program; HEl-2010: Healthy Eating Index-2010; US ERS: US Economic Research Service}

\section{Supplementary Information}

The online version contains supplementary material available at https://doi. org/10.1186/s12889-021-11465-6.

Additional file 1. Foodnest year 2 survey: food shopping, food access, nutrition \& health.

\section{Acknowledgements}

Not applicable.

\section{Authors' contributions}

ARB contributed to conceptualization of the manuscript, writing the original draft of the manuscript, reviewing and editing the manuscript, and visualization of the data. BAB contributed to conceptualization of the manuscript, methodology used in analysis of the data, programming for analysis of the data, validation of methods used, formal analysis of the data, data curation, writing of the original draft, and review of the manuscript draft. Methodology, Programming, Validation, Formal Analysis, Data Curation, Writing-Original draft, Writing-Review \& Editing. DN contributed to conceptualization of the manuscript draft, programming and formal analysis of the data, data curation, visualization of the data, and review of the manuscript draft. ME contributed to writing of the original manuscript draft, data analysis, visualization of the data, and project administration. DAF contributed to conceptualization of the project and original manuscript, investigation, provided resources for the project, writing and review of the manuscript draft, supervision and project administration, as well as funding acquisition. DJC contributed resources and funding acquisition for the project, conceptualization of the original manuscript, writing of the manuscript, review of the original draft, and supervision of the project. The author(s) read and approved the final manuscript.

\section{Funding}

This research was supported by grants from the National Institute of Diabetes and Digestive and Kidney Diseases (R01DK108184), Foundation for Food \& Agriculture Research (560290), National Dairy Council (2923), Michael \& Susan Dell Foundation(no grant number), and Nationwide Children's Hospital (no grant number). Findings and conclusions in this publication are those of the authors and do not necessarily represent the official position of the funding agencies.

Availability of data and materials

The datasets used and/or analyzed during the current study are available from the corresponding author on reasonable request.

\section{Declarations}

Ethics approval and consent to participate

The Case Western Reserve University (CWRU) Institutional Review Board issued approval for study activities, and participants verbally completed the informed consent process either over the phone, or in person, prior to 
participation. The CWRU IRB approved obtaining verbal consent and waived participant signatures, given that those potentially interested in participation could contact study staff over the phone. Approval was given for this waiver of signature, as the research activities presented no more than minimal risk or harm to participants and did not involve procedures for which written consent is normally required outside of the research context. In addition, the survey questions are similar to those encountered during normal daily life, posing no more than minimal risk.

\section{Consent for publication}

Not applicable.

\section{Competing interests}

DJC is an unpaid board member of the Ohio Commission on Minority Health and the Health Policy Institute of Ohio. Both entities address social determinants of health.

\section{Author details}

${ }^{1}$ Center for Child Health Equity and Outcomes Research, The Abigail Wexner Research Institute at Nationwide Children's Hospital, 700 Children's Drive, Columbus, OH 43205, USA. ${ }^{2}$ School of Education and Human Development, University of Virginia, Charlottesville, VA, USA. ${ }^{3}$ Department of Population and Quantitative Health Sciences, Case Western Reserve University, Cleveland, $\mathrm{OH}$, USA. ${ }^{4}$ Department of Pediatrics, The Ohio State University College of Medicine, Columbus, $\mathrm{OH}$, USA.

Received: 6 October 2020 Accepted: 5 July 2021

Published online: 16 July 2021

\section{References}

1. U.S. Department of Agriculture ERS. Food Security Status of U.S. Households in 20182019 Available from: https://www.ers.usda.gov/topics/foodnutrition-assistance/food-security-in-the-us/key-statistics-graphics.a spx\#foodsecure.

2. U.S. Department of Agriculture ERS. Definitions of Food Security 2019 Available from: https://www.ers.usda.gov/topics/food-nutrition-assistance/ food-security-in-the-us/definitions-of-food-security/.

3. Bruening M, MacLehose R, Loth K, Story M, Neumark-Sztainer D. Feeding a family in a recession: food insecurity among Minnesota parents. Am J Public Health. 2012;102(3):520-6. https://doi.org/10.2105/AJPH.2011.300390.

4. Champagne CM, Casey PH, Connell CL, Stuff JE, Gossett JM, Harsha DW, et al. Poverty and food intake in rural America: diet quality is lower in food insecure adults in the Mississippi Delta. J Am Diet Assoc. 2007;107(11):188694. https://doi.org/10.1016/j.jada.2007.08.003.

5. Liu Y, Njai RS, Greenlund KJ, Chapman DP, Croft JB. Relationships between housing and food insecurity, frequent mental distress, and insufficient sleep among adults in 12 US states, 2009. Prev Chronic Dis. 2014;11:E37.

6. Pruitt SL, Leonard T, Xuan L, Amory R, Higashi RT, Nguyen OK, et al. Who is food insecure? Implications for targeted recruitment and outreach, national health and nutrition examination survey, 2005-2010. Prev Chronic Dis. 2016; 2016(13):160103.

7. Hanson KL, Connor LM. Food insecurity and dietary quality in US adults and children: a systematic review. Am J Clin Nutr. 2014;100(2):684-92. https:// doi.org/10.3945/ajcn.114.084525.

8. Leung CW, Tester JM. The association between food insecurity and diet quality varies by race/ethnicity: an analysis of National Health and nutrition examination survey 2011-2014 results. J Acad Nutr Diet. 2019;119(10):167686. https://doi.org/10.1016/j.jand.2018.10.011.

9. Widome R, Neumark-Sztainer D, Hannan PJ, Haines J, Story M. Eating when there is not enough to eat: eating behaviors and perceptions of food among food-insecure youths. Am J Public Health. 2009;99(5):822-8. https:// doi.org/10.2105/AJPH.2008.139758.

10. Butcher LM, Ryan MM, O'Sullivan TA, Lo J, Devine A. Food-insecure Household's self-reported perceptions of food labels, product attributes and consumption behaviours. Nutrients. 2019;11(4):828

11. Burke MP, Martini LH, Blake CE, Younginer NA, Draper CL, Bell BA, et al. Stretching food and being creative: caregiver responses to child food insecurity. J Nutr Educ Behav. 2017;49(4):296-303.e1.

12. Gorman KS, McCurdy K, Kisler T, Metallinos-Katsaras E. Maternal strategies to access food differ by food security status. J Acad Nutr Diet. 2017;117(1):4857. https://doi.org/10.1016/j.jand.2016.07.010.
13. Spees CK, Clark JE, Hooker NH, Watowicz RP, Taylor CA. Dietary intake contributions of food and beverages by source and food security status in US adults. J Nutr Educ Behav. 2017:49(8):667-73.e1.

14. Council on Community Pediatrics CoN. Promoting food security for all children. Pediatrics. 2015;136(5):e1431-e8. https://doi.org/10.1542/peds.201 5-3301.

15. Palakshappa D, Vasan A, Khan S, Seifu L, Feudtner C, Fiks AG. Clinicians' perceptions of screening for food insecurity in suburban pediatric practice. Pediatrics. 2017;140(1):e20170319.

16. Barnidge E, LaBarge G, Krupsky K, Arthur J. Screening for food insecurity in pediatric clinical settings: opportunities and barriers. J Community Health. 2017:42(1):51-7. https://doi.org/10.1007/s10900-016-0229-z.

17. Marpadga S, Fernandez A, Leung J, Tang A, Seligman H, Murphy EJ. Challenges and successes with food resource referrals for food-insecure patients with diabetes. Perm J. 2019;23:18-097.

18. Garg A, Toy S, Tripodis Y, Silverstein M, Freeman E. Addressing social determinants of health at well child care visits: a cluster RCT. Pediatrics. 2015;135(2):e296-304. https://doi.org/10.1542/peds.2014-2888.

19. Freedman DA, Bell BA, Clark J, Ngendahimana D, Borawski E, Trapl E, et al. Small improvements in an urban food environment resulted in no changes in diet among residents. J Community Health. 2021;46:1-12.

20. Centers for Disease Control and Prevention (CDC). Behavioral risk factor surveillance system survey. Atlanta, Georgia: U.S. Department of Health and Human Services, Centers for Disease Control and Prevention; 2003.

21. Guenther PM, Casavale KO, Reedy J, Kirkpatrick SI, Hiza HA, Kuczynski KJ, et al. Update of the healthy eating index: HEI-2010. J Acad Nutr Diet. 2013; 113(4):569-80. https://doi.org/10.1016/j.jand.2012.12.016.

22. Cheema JR. Some general guidelines for choosing missing data handling methods in educational research. J Mod Appl Stat Meth. 2014;13(2):53-75. https://doi.org/10.22237/jmasm/1414814520.

23. Smith S, Malinak D, Chang J, Perez M, Perez S, Settlecowski E, et al. Implementation of a food insecurity screening and referral program in student-run free clinics in San Diego, California. Prev Med Rep. 2016;5:134-9.

24. Swann CA. Household history, SNAP participation, and food insecurity. Food Policy. 2017;73:1-9. https://doi.org/10.1016/j.foodpol.2017.08.006.

25. Gundersen C, Kreider B, Pepper JV. Partial identification methods for evaluating food assistance programs: a case study of the causal impact of SNAP on food insecurity. Am J Agric Econ. 2017;99(4):875-93. https://doi. org/10.1093/ajae/aax026.

26. Steele-Adjognon $M$, Weatherspoon D. Double up food bucks program effects on SNAP recipients' fruit and vegetable purchases. BMC Public Health. 2017;17(1):946. https://doi.org/10.1186/s12889-017-4942-z.

27. Cohen AJ, Richardson CR, Heisler M, Sen A, Murphy EC, Hesterman OB, et al. Increasing use of a healthy food incentive: a waiting room intervention among low-income patients. Am J Prev Med. 2017;52(2):154-62. https://doi. org/10.1016/j.amepre.2016.11.008.

28. Ma X, Liese AD, Hibbert J, Bell BA, Wilcox S, Sharpe PA. The association between store-specific and overall food shopping behaviors and household food security. Ann Epidemiol. 2015;25(9):717. https://doi.org/10.1016/j.a nnepidem.2015.06.072.

29. Fiori K, Patel M, Sanderson D, Parsons A, Hodgson S, Scholnick J, et al. From policy statement to practice: integrating social needs screening and referral assistance with community health Workers in an Urban Academic Health Center. J Prim Care Community Health. 2019;10:2150132719899207.

30. Bell ON, Hole MK, Johnson K, Marcil LE, Solomon BS, Schickedanz A Medical-financial partnerships: cross-sector collaborations between medical and financial services to improve health. Acad Pediatr. 2020;20(2):166-74. https://doi.org/10.1016/j.acap.2019.10.001.

31. Temple JB. The association between stressful events and food insecurity: cross-sectional evidence from Australia. Int J Environ Res Public Health. 2018;15(11):2333.

32. Jones SJ, Draper CL, Bell BA, Burke MP, Martini L, Younginer N, et al. Child hunger from a family resilience perspective. J Hunger Environ Nutr. 2018; 13(3):340-61. https://doi.org/10.1080/19320248.2017.1364189.

\section{Publisher's Note}

Springer Nature remains neutral with regard to jurisdictional claims in published maps and institutional affiliations. 